\title{
APPROACHES FOR OPTIMIZING MEDICAL AID IN ACUTE ISCHEMIC STROKE PATIENTS, HOSPITALIZED IN UMHAT „SAINT MARINA“ - VARNA
}

\author{
Silva Andonova, Darina Georgieva-Hristova, Evgeniya Kalevska \\ Second Neurology Clinic, UMHAT „St. Marina“, Medical University of Varna
}

\begin{abstract}
In Bulgaria treatment of acute ischemic strokes is performed at neurology or internal diseases wards in smaller hospitals, intensive care wards in state regional hospitals or ischemic stroke units and intensive care wards for treatment of neurological diseases at university hospitals. A prospective study was carried in the period 2009 - 2013, with the aim of optimizing the treatment of acute ischemic stroke (AIS) patients, hospitalized at the Neurology Clinic of UMHAT-St. Marina. The gradual introduction of innovative treatment methods including intravenous thrombolysis and endovascular therapy of AIS patients, into everyday clinical practice, as well as organizational restructurations in view of optimizing the care for such patients led to the improvement of some quality indicators.
\end{abstract}

Keywords: acute ischemic stroke, optimizing, medical aid

\section{INTRODUCTION}

Based on the data published on the site of the National Statistical Institute of all 47276 hospitalized patients with ischemic stroke in Bulgaria for 2014, only $0.4 \%$ (216) had thrombolytic therapy, and $0.2 \%$ - endovascular therapy (CEA or CTA). The remaining $99.4 \%$, had unspecified therapy (1). Between 2005 and 2014 the number of thrombolyses as specific treatment of acute ischemic stroke, grew continuously. In 2006 the thrombolyses were 19, while in 2014, they were 216 .

\footnotetext{
Address for correspondence:

Darina Georgieva

Department of Neurology and Neurosciences,

Medical University of Varna

55 Marin Drinov Str.

9002 Varna, Bulgaria

e-mail: georgieva.dk@abv.bg
}

Received: October 19, 2015

Accepted: December 15, 2015
As compared to the EU countries, the frequency of thrombolytic therapy of acute ischemic stroke in Bulgaria remains significantly low - varying over the years between $0.3 \%$ and $1.2 \%$ annually, while the recommended minimum is $1-2 \%$. $(1,5,7,10)$.

The analysis on the number of patients with AIS in the Neurology clinic of UMHAT- St. Marina between 2012-2014 and the severity of the condition provided grounds for establishing a specialised ward for the treatment of acute strokes - "stroke unit". The goals of the new ward relate to the completion of the diagnostic testing, clarifying further therapy, determining and correcting main risk factors, clinical improvement, stabilization of the patient's condition and starting early rehabilitation. For that purpose, two rehabilitation therapists were employed at the clinic $(4,14)$.

\section{AIM}

The aim is to develope a model for management, monitoring and quality control of medical activities in patients with acute cerebrovascular accidents. 
Silva Andonova, Darina Georgieva-Hristova, Evgeniya Kalevska

\section{MATERIAL AND METHODS}

The present prospective study is carried out in the period 2009-2013 and includes 5353 patients with acute ischaemic stroke hospitalised in the newly established stroke unit at UMHAT- St. Marina.

All patients underwent through a newly introduced complex AIS management coordinating the efforts of the emergency centre, the hospital emergency room and different specialists from the image diagnostics department, the clinical laboratory, the intensive neurological unit and the ward for treatment of acute strokes.

The effect of the management intervention was assessed with the following quality indicators: period from onset of AISH to hospitalisation; \% hospitalized up to the $3^{\text {rd }}$ hour; \% head CT; \% with early rehab;
Varna city/region at our clinic has been organized on the principles of multidisciplinary approach, team work and a full coordination between separate units engaged in this activity.

AIS management combines the efforts of the emergency centre, the emergency room at the hospital and different specialists from the image diagnostics department, the clinical laboratory, the intensive neurological unit and the ward for treatment of acute strokes. The communication and good cooperation between these units have proven exceptionally beneficial for timely treatment (8).

As a result of the continuous organisational meetings and staff training, the number the AIS patients treated with thrombolysis has increased (Table 1).

Table 1. Characteristics of AIS patients treated with thrombolysis

\begin{tabular}{cc|c|cc} 
Year & AIS patients & $\begin{array}{c}\text { TL/ } \\
\mathbf{n}(\%)\end{array}$ & $\begin{array}{c}\text { Average age } \\
\text { (years) }\end{array}$ & $\begin{array}{c}\text { Men/women } \\
\text { n }\end{array}$ \\
2009 & 1147 & $16(1.4 \%)$ & $54(34-75)$ & $11 / 5$ \\
2010 & 1123 & $27(2.4 \%)$ & $60(32-73)$ & $19 / 8$ \\
2011 & 1105 & $28(2.5 \%)$ & $63(45-75)$ & $18 / 10$ \\
2012 & 1019 & $46(4.5 \%)$ & $68(43-89)$ & $24 / 22$ \\
2013 & 959 & $49(5.1 \%)$ & $72(35-85)$ & $20 / 29$ \\
\hline
\end{tabular}

$\%$ inhospital deaths; moratlity up to the 3rd month; neurological status at $24^{\text {th }}$ hour, $7^{\text {th }}$ day, at dehospitalization and on the $3^{\text {rd }}$ month, assessed with the modified Rankin scale as well as NIHSS at the $24^{\text {th }}$ hour and $7^{\text {th }}$ day.

The quality indicators from our hospital management were compared with the average reported from six european countries. The neurological status of our paitents at the $24^{\text {th }}$ hour and $7^{\text {th }}$ day was compared with that of patients registered in SITS.

Statistical analyses included estimation of mean or median values (for variables without normal distribution) and 95\% confidence interval. Qualitative variables were presented as percentages and 95\% confidence intervals.

\section{RESULTS}

Owing to the efforts of different institutions and the support of the management team of UMHAT Saint Marina, the care for AIS patients from
The clinic has developed and implemented its own clinical protocols on the basis of existing European and national standards, as well as technical nursing care cards $(3,9)$.

Quality indicators for the management of AIS patients with and without TL at our center were compared with the results from six European countries - Belgium, England Germany, Sweden, Spain, Scotland, published by the European Implementation Score Collaborative, presented in table 2 (17).

The selected quality indicators show significant improvement in 2013 as compared to 2009, which allows us to use them for the assessment of the effect of the algorithm on the AIS treatment.

The ESO recommends continuous control of the routine application of TL therapy for AIS patients $(2,3,5)$.

An example of this is the International Stroke Thrombolysis Register (SITS) created for control of 
Approaches for optimizing medical aid in acute ischemic stroke patients, hospitalized in UMHAT „Saint Marina“- Varna

Table 2. Comparative Analysis of some quality indicators (analyzed in the EIS research) in patients with/without AIS at our center for 2009 and 2013

\begin{tabular}{|c|c|c|c|c|c|}
\hline Quality Indicator & $\begin{array}{l}\text { without TL } \\
2009\end{array}$ & $\begin{array}{l}\text { without TL } \\
2013\end{array}$ & $\begin{array}{l}\text { with TL } \\
2009\end{array}$ & $\begin{array}{l}\text { with TL } \\
2013\end{array}$ & $\begin{array}{c}\% \\
\text { EIS } \\
\text { reporting }\end{array}$ \\
\hline Thrombolyses & - & - & $1.4 \%$ & $5.1 \%$ & 60 \\
\hline Onset of AISH - EU & $1604 \mathrm{~min}$ & $1430 \mathrm{~min}$ & $62.8 \mathrm{~min}$ & $84.4 \min ^{*}$ & 38 \\
\hline Hospitalized up to the $3^{\text {rd }}$ hour & $1 \%$ & $3 \%$ & $39 \%$ & $62 \%$ & 40 \\
\hline CT of head & $96 \%$ & $95 \%$ & $100 \%$ & $100 \%$ & 72 \\
\hline Early rehab & $12 \%$ & $72 \%$ & $42 \%$ & $84 \%$ & 50 \\
\hline Death rate during hospitalization & $24 \%$ & $19.9 \%$ & $22 \%$ & $9.3 \%$ & 20 \\
\hline Death rate up to the $3^{\text {rd }}$ month & $23 \%$ & $22.3 \%$ & $22.5 \%$ & $23.7 \%$ & 32 \\
\hline $\begin{array}{l}\text { Disability level after } \\
\text { dehospitalization (mRS 3-6) }\end{array}$ & $84.3 \%$ & $89 \%$ & $77.2 \%$ & $68 \%$ & 30 \\
\hline Disability level at $3 \mathrm{~m}(\mathrm{mRS} 3-6)$ & $66.5 \%$ & $50 \%$ & $53.9 \%$ & $44 \%$ & 30 \\
\hline
\end{tabular}

*Increase of the time relating to an increase of the therapeutic window from 3 to $4.5 \mathrm{~h}$.

Table 3. Results from the outcome of TL treatment of patients during hospitalization

\begin{tabular}{|c|c|c|c|c|}
\hline \multirow{2}{*}{$\begin{array}{l}\text { Clinical } \\
\text { outcome } \\
\text { NIHSS (24h) }\end{array}$} & \multicolumn{2}{|c|}{$\begin{array}{l}\text { Saint Marina - Varna (BGSVE) } \\
\text { Second neurology clinic }\end{array}$} & \multicolumn{2}{|c|}{ Data from SITS ${ }^{\star}$} \\
\hline & mean $(\mathrm{CI})$ & median (IQR) (N) & mean $(\mathrm{CI})$ & median (IQR) (N) \\
\hline NIHSS (24h) & $11.50(10.25-12.76)$ & $\begin{array}{c}10.00(5.00-16.00) \\
(137)\end{array}$ & $8.41(8.35-8.47)$ & $\begin{array}{c}6.00(2.00-14.00) \\
(73503)\end{array}$ \\
\hline NIHSS (7d) & mean $(\mathrm{CI})$ & median (IQR) (N) & mean $(\mathrm{CI})$ & $\operatorname{median}(\mathrm{IQR})(\mathrm{N})$ \\
\hline NIHSS (7d) & $10.00(9.55-10.45)$ & $\begin{array}{c}7.00(3.00-13.00) \\
(1572)\end{array}$ & $6.35(6.29-6.40)$ & $\begin{array}{c}3.00(1.00-10.00) \\
(66137)\end{array}$ \\
\hline $\begin{array}{l}\text { Global } \\
\text { outcome (24h) }\end{array}$ & $\%(\mathrm{CI})$ & $\mathrm{n} / \mathrm{N}$ & $\%(\mathrm{CI})$ & $\mathrm{n} / \mathrm{N}$ \\
\hline Much better & $25.36(18.84-33.22)$ & $35 / 138$ & $30.75(30.43-31.07)$ & 24702 / 80339 \\
\hline Better & $28.99(22.07-37.04)$ & $40 / 138$ & $32.08(31.75-32.40)$ & 25769 / 80339 \\
\hline Unchanged & $39.13(31.39-47.46)$ & $54 / 138$ & $23.25(22.96-23.54)$ & 18679 / 80339 \\
\hline Worse & $1.45(0.40-5.13)$ & $2 / 138$ & $8.82(8.62-9.01)$ & 7082 / 80339 \\
\hline Much worse & $4.35(2.01-9.16)$ & $6 / 138$ & $4.01(3.88-4.15)$ & 3224 / 80339 \\
\hline Dead & $0.72(0.13-3.99)$ & $1 / 138$ & $1.10(1.03-1.17)$ & 883 / 80339 \\
\hline $\begin{array}{l}\text { Global } \\
\text { outcome (7d) }\end{array}$ & $\%(\mathrm{CI})$ & $\mathrm{n} / \mathrm{N}$ & $\%(\mathrm{CI})$ & $\mathrm{n} / \mathrm{N}$ \\
\hline Much better & $37.12(29.35-45.62)$ & $49 / 132$ & $41.44(41.09-41.78)$ & $32009 / 77249$ \\
\hline Better & $32.58(25.17-40.96)$ & $43 / 132$ & $29.40(29.08-29.72)$ & $22713 / 77249$ \\
\hline Unchanged & $15.15(10.03-22.25)$ & $20 / 132$ & $14.98(14.73-15.23)$ & 11569 / 77249 \\
\hline Worse & $3.79(1.63-8.56)$ & $5 / 132$ & $4.91(4.76-5.06)$ & $3792 / 77249$ \\
\hline Much worse & $4.55(2.10-9.56)$ & $6 / 132$ & $2.73(2.62-2.84)$ & $2107 / 77249$ \\
\hline Dead & $6.82(3.63-12.45)$ & $9 / 132$ & $6.55(6.38-6.73)$ & $5059 / 77249$ \\
\hline
\end{tabular}

* SITS data 
Silva Andonova, Darina Georgieva-Hristova, Evgeniya Kalevska

the safety and efficiency of the routine therapeutic application of rt-PA in acute ischemic strokes.

As of 2009, the clinic has been implementing TL therapy, and as of 2011, Second Neurology Clinic at UMHAT Saint Marina has been registered as a center with the SITS. Currently 1134 centers participate. At the end of 2013, five more centers have been included from Bulgaria, whose analysis is pending. The Centre in Varna is one of the first in Europe with 3-month monitoring of patients after AIS diagnosis.

As there is no national register of acute ischemic stroke patients in Bulgaria, in order to analyze the research data relating to optimization of stroke treatment and care, we have to compare the data from our clinic to the database in the other centers included in SITS.

Comparison of treatment outcomes on the seventh day of hospitalization between our clinic and SITS is shown in table 3.

As percentage of patients with more severe motion deficit as measured with NIHSS is bigger at our center, as compared to other centers in the register.

The comparison of the treatment outcomes in patients with TL during hospitalization between our center and the other centers show that the largest percentage of patients are with favorable or very favorable outcome from the treatment - around $70 \%$ $(12,13,15)$.

There is no significant difference in the results between our center and the rest of the centers. Around the same percentage of patients have deteriorated - 7\%, or died during hospitalization (Table 3) $(11,15)$.

\section{DISSCUSSION}

AIS patients must by definition be treated in Stroke Units $(5,10)$. Comprehensive stroke units have been set up for the needs of complicated cases and cases suitable for endovascular therapy. The emergency CT of head on admittance of the patient to the hospital is very important for determining the diagnosis - ischemic or hemorrhagic stroke (14). It has to be done as soon as possible if there are any assumption of a stroke. The neurological status and vital signs of stroke patients must be recorded regularly in the acute stage.
The timely diagnosis and treatment of the risk factors lies at the basis of stroke treatment (16). Intravenous treatment with $r t-P A$ in acute ischemic stroke must be carried out within 4.5 hours after the onset, in centers experienced in TL treatment (8).

In order to decrease time from the beginning of the hospitalization to the start of the treatment, the Emergency Hopsital Units should be informed in due time that acute stroke patient is being transported (9). After hospitalization of the patient at the emergency unit, it is recommended that he/she is examined within 10 minutes after admittance by a neurologist, before the head CT which has to be done up to the $25^{\text {th }}$ minute of admittance.

Fast and correct assessment of the therapeutic possibilities is needed, based on the emergency clinical tests and the existing changes in the neural imaging tests (1).

The percentage increase of thrombolytic therapies is also connected with the continuous training of the staff implementing this therapy (15). It is necessary to set up training centers and training standards: of the population, Emergency Centers' staff, stroke ward teams, the leading stroke centers' teams, of the neuro-interventionist specialists.

Increased work organization efficiency is necessary in view of decreasing time intervals recommended in the existing standards of AHA and ESO.

The standards recommend commencement of therapy within 60 minutes of admittance, („Door-toNeedle") (10).

Patient satisfaction can be deemed a result from the medical care. By measuring patient satisfaction and patient needs, the goals of the organization are streamlined and the activities are toptimized.

It is necessary that the Second Neurology Clinic at UMHAT Saint Marina continues its international cooperation as part and member of the SITS register, which will guarantee stable harmonization of the activities with the different international initiatives in this sphere; pooling of experience, results, interventions, qualification of staff - physicians and nurses, assessment of results, determining the best practicies and approaches for treatment of acute ischemic stroke.

Acute ischemic stroke management should be based on a more assertive and active treatment strat- 
egy. The internal protocols for diagnosis and treatment of AIS patients developed on the basis of scientific research and the existing international and national standards must contain well-documented activities for fast and precise diagnostics, including neurologic assessment and a CT of head, due treatment complying with the standard and continuous monitoring for prevention of register documented complications (6). It necessitates the introduction of clinical practice of endovascular treatment of acute strokes, as well as an increase of the number of patient treated with thrombolysis.

The problem of quality in health care is especially poignant now in the context of constant competition between health care establishment, and increased expectations of patients and the society as a whole of the quality of health care services.

The maintaining of high quality levels of health care services can be achieved by an integral improvement of the activities in all their aspects, by implementing total quality management and monitoring. Improvement of quality is of crucial significance both for improving the health and quality of life of the popuation and for ensuring effective development of health care organizations and increasing their competitiveness.

\section{CONCLUSION}

* Based on the analysis of the data from the papers and the five-year research, we offer the introduction of Quality Indicators on a national Bulgarian level, related to the optimization of acute stroke management as follows:

* \% AIS patients, treated at the stroke ward;

* Number of thrombolyses per year;

* Number of neuro-imaging tests of brain vessels in the acute stage;

* Average admittance time at the Emergency Ward until the beginning of the treatment;

* Average time from onset of symptoms to Emergency Ward;

* Average duration of hospital stay;

* Outcome of the treatment (disability and dehospitalization, death rate/disability on the $3^{\text {rd }}$ month);

* Hospital lethality without/with registered complications;
* Number of trainings per year (of patients, their relatives, Emergency Care Centre staff, staff at the clinic).

It is necessary to introduce efficient management and coordination of the activities not only at hospitals, but on a regional level as well; creating institutional capacity for timely introduction of the existing standards for treatment of acute ischemic stroke patients (17).

The prioritizing of the specific treatment of AIS is the main task of every hospital and health care system. It is necessary to introduce effective measures for implementation of the activities not only in the hospital but in the region as well (17).

\section{REFERENCES}

1. Tityanova E, Velcheva I, Andonova S. Stroke in Bulgaria: Current Issues. Neurosonology and Cerebral Hemodynamics. 2015;11:7-13.

2. Abilleira S, Gallofré M, Ribera A, Sánchez E, Tresserras R. Quality of in-hospital stroke care according to evidence-based performance measures: results from the first audit of stroke, Catalonia, Spain. Stroke. 2009;40:1433-8.

3. Adams HP, del Zoppo G; Alberts MJ. Guidelines for the early management of adults with ischemic stroke: Aguideline from the American Heart Association/American Stroke Association Stroke Council, Clinical Cardiology Council, Cardiovascular Radiology and Intervention Council, and the Atherosclerotic Peripheral Vascular Disease and Quality of Care Outcomes in Resaerch Interdisciplinary Working Groups.scientific statement from the Stroke Council of the American Stroke Association. Stroke. 2007;38:1655-711.

4. Alberts MJ, Latchaw RE, Selman WR. Brain Attack Coalition. Recommendations for comprehensive stroke centers: a consensus statement from the Brain Attack Coalition. Stroke. 2005;36:1597-616.

5. Audebert H, Kukla C, Vatankhah B et al. Comparison of tissue plasminogen activator administration management between Telestroke Network hospitals andacademic stroke centers: the Telemedical Pilot Project for Integrative Stroke Care in Bavaria. Stroke 37, 2006: 1822-1827.

6. Eissa A, Krass I, Bajorek B. Optimizing the management of acute ischaemic stroke: a review of the utilization of intravenous recombinant tissue plas- 
minogen activator (tPA). Journal of Clinical Pharmacy and Therapeutics. 2012;37:620-9.

7. Eissa A, Krass I, Bajorek B. Barriers to the utilization of thrombolysis for acute ischaemic stroke. Journal of Clinical Pharmacy and Therapeutics 23, 2012: 211-221.

8. European Stroke Organisation. Guidelines for management of ischaemic stroke and transient ischaemic attack. Stroke. 2002;33:2850-7.

9. European Stroke Organisation (ESO) Executive Committee; ESO Writing Committee. Guidelines for management of ischaemic stroke and transient ischaemic attack 2008. Cerebrovasc Dis. 2008;25:457-507.

10. Ferrari J, Knoflach M, Kiechl S, Willeit J, Matošević B. For the Austrian Stroke Unit Registry Collaborators. Stroke Thrombolysis: Having More Time Translates Into Delayed Therapy. Stroke. 2010;41:2-5.

11. Heuschmann PU, Busse O, Wagner M. Frequency and care of stroke in Germany. Akt Neurologie. 2010;37:333-40.

12. Heuschmann PU, Biegler MK, Busse O. Development and implementation of evidence-based indicators for measuring quality of acute stroke care: the Quality Indicator Board of the German Stroke Registers Study Group (ADSR). Stroke. 2006;37:2573-8.

13. Meretoja A, Roine RO, Kaste M, Linna M, Juntunen M, Erilä T. Stroke monitoring on a national level: PERFECT Stroke, a comprehensive, registry-linkage stroke database in Finland. Stroke. 2010;41:2239-46.

14. Nabavi DG, Ringelstein EB, Faiss J. Regional and national stroke units in Germany: amended certification criteria. Nervenarzt. 2012;83:1039-52.

15. Nimptsch U, Mansky T. Trends in acute inpatient stroke care in Germanyan observational study using administrative hospital data from 2005-2010. Dtsch Arztebl Int. 2012;109:885-92.

16. Reeves MJ, Parker C, Fonarow GC, Smith EE, Schwamm LH. Development of stroke performance measures: definitions, methods, and current measures. Stroke. 2010;41:1573-8.

17. Wiedmann S, Norrving B, Nowe T. Variations in quality indicators of acute stroke care in 6 European countries: the European Implementation Score (EIS) Collaboration. Stroke. 2012;43:458-63. 